\title{
Condições de saúde no Brasil Colônia: Primórdios da Higiene Pública como Política Governamental no Rio de Janeiro dos Vice-reis
}

\author{
Vinicius Cranek Gagliardo. ${ }^{1}$
}

Durante o período colonial, o sistema produtivo instituído pela coroa portuguesa, que privilegiou o desenvolvimento de uma economia essencialmente agrária e de exportação, acabou por desprestigiar a formação de núcleos urbanos no Brasil.² Excetuando-se as cidades litorâneas em que se encontravam os principais portos, a cidade de São Paulo e as concentrações urbanas resultantes das zonas de mineração, que se tornariam as mais importantes urbes em fins dos tempos coloniais, a situação da América portuguesa era predominantemente rural, prevalecendo as grandes propriedades latifundiárias, comandadas pelas famílias senhoriais (Costa, 2007, p. 236).

Devido à política de ocupação do território praticada pela corte lusitana, que transferiu à iniciativa privada o encargo de povoar os trópicos, os colonos impuseram à terra a ordem social que lhes pareceu mais adequada aos seus interesses, governando, em larga medida, de acordo com suas vontades durante os três primeiros séculos de colonização. À metrópole coube o papel de controlar os excessos dos colonos quando seus interesses destoavam dos da monarquia portuguesa. Desse modo, a família

\footnotetext{
${ }^{1}$ Doutorando em História na Universidade Estadual Paulista "Julio de Mesquita Filho", campus de Franca (UNESP/Franca). Bolsista FAPESP. Autor de "Uma Paris dos trópicos? A europeização do Rio de Janeiro oitocentista". São Paulo: Alameda Casa Editorial Ltda, 2013 (No Prelo)

${ }^{2}$ Segundo Sergio Buarque de Holanda, "não devia ser muito favorável às cidades a comparação entre a vida urbana e a rural". Segundo o autor, "ainda durante a segunda metade do século XVIII persistia bem nítido o estado de coisas que caracteriza a nossa vida colonial desde os seus primeiros tempos. A pujança dos domínios rurais, comparada à mesquinhez urbana, representa fenômeno que se instalou aqui com os colonos portugueses, desde que se fixaram à terra". (Holanda, 1995, p. 91).
}

Brasiliana - Journal for Brazilian Studies. Vol. 2, n.2 (Nov 2013). ISSN 2245-4373. 
latifundiária, estruturada em torno dos senhores de engenho, acumulou, no decorrer do tempo, uma quantidade de poder que passou a rivalizar com o poder da coroa. Foi em razão desta situação que os mesmos senhores rurais criaram os primeiros núcleos urbanos no Brasil, imprimindo suas marcas em toda a estrutura citadina colonial, moldada como extensão da grande propriedade e meio de afirmação das famílias rurais (Costa, 2004, p. 36-39). Assim, durante o século XVIII, as cidades tornaram-se o principal centro de contestação dos interesses metropolitanos, obrigando Portugal, que até então havia sido bastante negligente em relação à política de povoamento e de urbanização do Brasil, a investir em medidas que reconduzissem as cidades à antiga ordem colonial, despertando um novo tipo de interesse pelas urbes de suas possessões da América (Ib., p. 19-20).

Na segunda metade do Setecentos, o exemplo mais significativo deste novo interesse da metrópole pelas cidades foi São Sebastião do Rio de Janeiro, interesse que não se deu somente pelo perigo da contestação vindo da cidade. Na verdade, desde o início do século XVIII, o Rio de Janeiro transformara-se no centro de controle dos objetivos da metrópole na América, protagonizando o papel de grande articulador da região centro-sul da colônia. Tal destaque foi resultado tanto de sua posição estratégica nos conflitos fronteiriços com a Espanha, na região sul do Brasil, como da situação de seu porto, o mais bem localizado para a exportação da produção aurífera (Bicalho, 2003, p. 84-85). É esta centralidade do Rio de Janeiro que foi reforçada com a transferência da capital do Brasil e o estabelecimento da sede do vice-reinado, ${ }^{3}$ em 1763, para a cidade

\footnotetext{
${ }^{3}$ Foram os seguintes os sete vice-reis do Brasil: Antônio Álvares da Cunha, o Conde da Cunha (1763-1767); Antônio Rolim de Moura Tavares, Conde de Azambuja, (1767-1769); Luiz de Almeida Portugal Soares d'Eça Alarcão Silva Mascarenhas, $2^{\circ}$ Marquês de Lavradio (1769-1779); Luiz de Vasconcelos e Souza (1779-1790); José Luiz de Castro, $2^{\circ}$ Conde de Rezende (1790-1801); Fernando José de Portugal (1801-1806); e Marcos de Noronha e Brito, $8^{\circ}$ Conde dos Arcos (1806-1808) (Barreto Filho; Lima, 1939, p. 81).
}

Brasiliana - Journal for Brazilian Studies. Vol. 2, n.2 (Nov 2013). ISSN 2245-4373. 
fluminense; ${ }^{4}$ posição central que o Rio de Janeiro manteria durante todo o século XIX, principalmente após o estabelecimento da monarquia na cidade, evento que desencadeou um processo de "reeuropeização" da América portuguesa. A partir de então, teria sido renovado e ampliado o contato do Brasil com a Europa, transformandose sua paisagem social que ainda se encontrava "com muita coisa de asiático, de mourisco, de africano: os elementos nativos deformados num sentido francamente oriental e não puramente português" (Freyre, 2004, p. 430). Com isso, ao recuar o olhar aos anos anteriores à transmigração da família real ao Brasil, sugere-se que a transferência do vice-reinado para o Rio de Janeiro, em 1763, inaugurou um novo tipo de preocupação com a cidade. Isso porque, como afirma Jurandir Freire Costa, "datam dessa época os primeiros esforços sistemáticos para controlar a cidade e a população em função dos interesses do Estado" (Costa, 2004, p. 20).

A despeito de seu grau de urbanização, fato é que o Rio de Janeiro passou a ocupar uma posição estratégica durante todo o século XVIII, posição que determinou um novo tipo de atenção com esta região por parte da metrópole, dando início a um período, em comparação com o restante do período colonial, de maior cuidado com a cidade. Assim, no campo da medicina, durante o século XIX, estabeleceu-se no Brasil uma nova política de saúde de abrangência social, com o deslocamento de seu objeto de intervenção do indivíduo para a sociedade, processo este que teve seu desenvolvimento

\footnotetext{
${ }^{4}$ Cabe ainda complementar que, de acordo com Maria Fernanda Bicalho, a transferência da sede do vice-reinado para o Rio de Janeiro não se deu apenas devido a sua posição na América portuguesa, mas em relação a sua centralidade em todo o Império português, dentro do quadro da geopolítica ultramarina e das disputas continentais europeias, uma vez que estas ameaçavam a própria preservação dos territórios coloniais no ultramar. Segundo Bicalho, "pela primeira vez na história da Europa os embates pioneiros e precursores dos conflitos continentais tiveram como palco privilegiado o espaço marítimo colonial. [...] Assim, em meados do século XVIII, os conflitos extracontinentais, ou seja, ultramarinos e coloniais, ganhavam vida própria, antecedendo e em parte determinando a própria guerra no território europeu, perdurando para além das negociações propriamente continentais" (Bicalho, 2003, p. 70).
}

Brasiliana - Journal for Brazilian Studies. Vol. 2, n.2 (Nov 2013). ISSN 2245-4373. 
na Europa desde o setecentos. ${ }^{5}$ Com este maior cuidado com as cidades a partir do século XVIII, a higiene pública tornou-se o grande pilar desta nova política de saúde que se consolidará no Brasil a partir do século XIX, distinguindo-se do modelo de medicina praticado desde os primórdios da ocupação portuguesa da América, cujo modo de intervenção ainda era a cura da enfermidade, e não a prevenção e manutenção de um estado contínuo de saúde (Machado et alli, 1978, p. 18-19). Em vista disso, este artigo tem por objetivo mapear as condições de saúde no Brasil Colônia, em especial os primórdios da higiene pública como política de governo, política esta que teria se desenvolvido no Rio de Janeiro a partir de meados do setecentos, principalmente durante o período dos vice-reis, e que se tornaria o principal sustentáculo da medicina social durante o Oitocentos.

\section{A medicina nos três primeiros séculos de colonização}

Desde o início da colonização do Brasil, os portugueses e os demais povos que vieram para os trópicos trouxeram consigo um grande número de doenças, desconhecidas dos nativos da região. Assim, a partir do século XVI, a América portuguesa foi sempre alvo das mais variadas epidemias e endemias (Ribeiro, 1971, p. 15-32); como explica Lycurgo Santos Filho:

\footnotetext{
${ }^{5}$ Michel Foucault refere-se a três etapas na formação da medicina social na Europa: a "medicina de Estado", que se desenvolveu, sobretudo, na Alemanha, desde o início do século XVIII, "com a organização de um saber médico estatal, a normalização da profissão médica, a subordinação dos médicos a uma administração central e, finalmente, a integração de vários médicos em uma organização médica estatal"; a "medicina urbana", que se desenvolveu na França em fins do século XVIII e que "não é verdadeiramente uma medicina dos homens, corpos e organismos, mas uma medicina das coisas: ar, água, decomposições, fermentos; uma medicina das condições de vida e do meio de existência", com o controle dos espaços comuns e dos lugares de circulação; e a "medicina dos pobres", desenvolvida na Inglaterra, no início do século XIX, "que é essencialmente um controle da saúde e do corpo das classes mais pobres para torná-las mais aptas ao trabalho e menos perigosas às classes mais ricas" (Foucault, 1979, p. 79 et. seq.).
}

Brasiliana - Journal for Brazilian Studies. Vol. 2, n.2 (Nov 2013). ISSN 2245-4373. 
[...] as entidades patológicas existentes no momento da descoberta, tais como a bouba ou piã, o bócio endêmico, parasitoses e dermatoses várias, disenterias e talvez o paludismo e a lues - o que ainda não se provou outras vieram ajuntar-se, carregadas pelos brancos colonizadores e pelos negros escravos. O branco veiculou varíola, o sarampo, a escarlatina, a tuberculose, a lepra, as doenças venéreas, parasitoses como a sarna e outras afecções, enquanto do continente africano provieram a filariose, a dracunculose ou bicho-da-costa, a febre amarela, a ancilostomíase e outras verminoses, o tracoma, o maculo, o ainhum ou mal perfurante plantar e o gundu ou exostose para-nasal. Somem-se a essas as diversas afecções dos aparelhos do corpo humano e estará mais ou menos delineada a patologia brasileira nos três primeiros séculos (Santos Filho, 1960, p. 151).

Apesar do acentuado e diversificado volume de doenças existentes, a medicina que se praticou no Brasil foi pautada pela carência de médicos ${ }^{6}$ e pela proliferação de todo tipo de curandeirismo. Antes do século XIX, não era possível encontrar, dentro do aparelho colonizador, a relação que hoje parece nítida entre saúde e população, pois a administração portuguesa não se dedicou a construir uma sociedade na qual o combate às causas das doenças e a manutenção de um estado contínuo de saúde coletiva fosse uma preocupação. Diferentemente do que se verá a partir do oitocentos, os primeiros séculos de colonização serão pautados pela ausência da ideia de prevenção, quando a

\footnotetext{
${ }^{6}$ Já durante o vice-reinado, em 1798, era apenas quatro o número de médicos atuando no Rio de Janeiro (Nava, 2003, p. 47).
}

Brasiliana - Journal for Brazilian Studies. Vol. 2, n.2 (Nov 2013). ISSN 2245-4373. 
medicina ocuparia somente a função de uma atividade de cura, sempre como uma solução a posteriori (Machado et alli, 1978, p. 154). Já a partir do século XIX, a medicina, atuando como dispositivo para o exercício do poder pelo Estado, passa a incorporar o social, trazendo para seu campo de saber o mundo urbano e intervindo positivamente sobre as cidades e seus habitantes.

Em vista disso, a saúde na colônia não foi tratada pela metrópole como uma prioridade. A perspectiva em vigor era muito mais combater o mal a despeito de cultivar o bem, o que não significa que não tenha existido uma atenção com a saúde dos colonos, já que era deles mesmos que dependia a manutenção e a preservação da possessão portuguesa, mas, sim, que a saúde "não aparece como algo que possa ser produzido, incentivado, organizado, aumentado. Embora encerre o máximo de positividade, só é percebida negativamente pela presença da realidade representada pela doença" (Id., p. 56). Desse modo, a falta de incentivo à saúde trouxe algumas consequências para a medicina praticada nos trópicos, como a já citada falta de médicos. Mas não se deve atribuir tal fato a um simples descaso por parte de Portugal, pois lá a situação também não era das melhores. Os lusitanos também não possuíam grande quantidade de médicos, sendo os existentes, normalmente, de baixa qualidade (Salles, 1971, p. 39). Isso porque o caráter cada vez mais científico da medicina que se desenvolveu no Velho Mundo, desde o século XVII, com suas Academias Científicas, pesquisas e descobertas, demorou cerca de um século a mais para introduzir-se em Portugal, ainda atrelado a uma educação comandada pelos jesuítas, que desfavorecia os estudos científicos em prol da teologia e da metafísica (Marques, 1999, p. 107-110). Mas, mesmo tendo em vista a situação da metrópole, o que dizer da falta dos médicos no Brasil? Explica-se em parte pela proibição do ensino superior no Brasil e pelas dificuldades que os jovens locais encontravam para estudar na Europa, bem como pelo 
diminuto interesse que a vida na colônia despertava, pois eram restritas as vantagens profissionais que o território oferecia (Nava, 2003, 152). Assim, foi baixo o número dos profissionais de saúde que atuaram no Brasil durante todo o período colonial, sendo a maior parte cristãos-novos de baixa camada social que abandonaram o continente europeu na esperança de viver com maior sossego longe da Inquisição (Santos Filho, 1947, p. 47).

No entanto, a falta de médicos não ocasionou a falta de indivíduos empenhados em curar. Desde o início da colonização, os portugueses encontraram entre os índios uma arte de curar dominada por conhecimentos empíricos, conhecimentos que eram sempre subordinados aos elementos da magia e do sobrenatural. A doença era, então, compreendida pelos ameríndios como resultado de castigos ou provações enviados pelo mundo místico, e, como tal, deveria ser combatida com as mesmas armas. A sua terapêutica consistia, sobretudo, na utilização dos recursos disponíveis na natureza, abundantemente recheada de plantas medicinais. Essas plantas seriam manipuladas pelo pajé, indivíduo que detinha amplo conhecimento das virtudes medicinais da flora local e que também baseava seu processo curativo na crença e no feiticismo, característicos de seu ambiente cultural (Ribeiro, 1971, p. 178-188).

É este o retrato da "medicina" encontrado pelos primeiros médicos e pelos jesuítas que vieram ao Brasil. Incluem-se os jesuítas pelo fato de os padres terem desenvolvido uma ampla rede de assistência médica durante o tempo em que permaneceram nos trópicos, de 1549 até sua expulsão, em 1759. Com a falta de profissionais graduados no ensino europeu circulando pela América portuguesa, tais religiosos atuaram como curadores entre a população nativa e os colonos que habitavam o território, uma vez que ou possuíam noções da arte de curar ou acabaram por aprendê-la empiricamente quando chegaram ao Novo Mundo. 
Numa época em que adquirir remédios vindos da Europa era extremamente difícil, e mesmo os que aqui podiam ser encontrados chegavam deteriorados pelo grande tempo que permaneciam nos navios até atingir os trópicos, os jesuítas e os médicos tiveram que se submeter aos costumes da terra, aprendendo a utilizar a flora local nos tratamentos a que submetiam os doentes (Santos Filho, 1960, p. 147). E, para isso, o conhecimento do indígena foi fundamental. O colono, que se manteve em constante intercâmbio com as práticas medicinais dos nativos, teve de adaptar seu arcabouço teórico obtido nas universidades às técnicas e aos conhecimentos do gentio. Tais saberes eram apreendidos e transmitidos à metrópole, que disseminou pela Europa as utilidades das plantas medicinais tropicais por meio da publicação de farmacopéias e tratados médicos, principalmente a partir do Setecentos, quando a medicina portuguesa tornou-se um pouco mais científica (Marques, 1999, p. 82). Até então, ela partilhava da mentalidade mágica presente na arte médica dos indígenas (Ribeiro, 1997, p. 87): de um lado, os jesuítas, que curavam em nome de Deus, pois percebiam as doenças como fruto do pecado; do outro, os médicos, cuja influência da igreja na formação impregnou a atividade de crenças e práticas sobrenaturais.

Ao saber dos índios e dos colonos juntou-se outro tipo de prática curativa: a dos negros. Todavia, sua contribuição foi pouco significativa nesta área, pois ficou circunscrita, basicamente, à utilização de plantas medicinais, utilização resultante do conhecimento empírico que possuíam, e aos recursos sobrenaturais que envolviam os rituais de cura; para Lycurgo Santos Filho:

[...] os conhecimentos e noções sobre a arte de curar trazidos pelos africanos não impressionaram quanto ao montante e nem quanto à qualidade. Contaminada pela feitiçaria, relacionada com a magia, 
praticada por feiticeiros-curadores ignorantes e embusteiros, a medicina dos negros perdeu-se em suas noções essenciais, terrenas, porque a parte sobrenatural de que estava eivada e sobrecarregada, persistiu entre os praticantes e disseminou-se pela população inculta. Os feiticeiros-curadores apresentavam-se como intermediários entre os deuses e os mortais. Deuses maus provocavam as doenças. Deuses bons curavam-nas. Sempre a mesma, a etiologia, entre os povos primitivos. A terapêutica resumia-se em raizadas e feitiços ou mandingas (Santos Filho, 1960, p. 160).

Como se pode notar, foram diversos os praticantes de medicina no Brasil colonial. Situação que encontra motivação basicamente na relação entre a ausência de médicos e a presença de diferentes tipos culturais convivendo num mesmo ambiente: se a ausência de profissionais graduados conferiu um importante papel ao desenvolvimento de outras artes de cura, como a dos jesuítas, índios e negros (Ribeiro, 1997, p. 16), também a própria presença de tão variadas tradições culturais no mesmo território abriu espaço para que a medicina de índios e negros se disseminasse, com seus curadores e terapêuticas próprios, desestimulando a ação de médicos e cirurgiões licenciados (Marques, 1999, p. 28). Desse modo, aqueles que atuaram como agentes curadores, tendo ou não competência e autorização para tal, desempenharam atividades terapêuticas bastante semelhantes, fomentando uma prática médica de características específicas, em que se fundiram diversos elementos culturais. Se os profissionais formados nas Universidades europeias traziam consigo os conhecimentos teóricos, afastando-se do saber empírico dos índios e negros, também se aproximavam destes 
últimos no que se refere ao mundo do sobrenatural e da magia, presente nas práticas médicas cotidianas; como diz Márcia Moisés Ribeiro:

[...] sem perder seus alicerces básicos, ao saber médico indígena acrescentou-se a experiência dos europeus e africanos. Noções e práticas muito familiares ao silvícola, outras absolutamente alheias, combinaram-se, dando origem à medicina dos tempos coloniais que nada mais é que o conjunto de conhecimentos, hábitos e práticas nascido a partir do convívio assíduo entre as três culturas. O saber oriundo do reino português atrelou-se à cultura indígena e africana ao sabor das circunstâncias oferecidas pela terra conquistada, originando um complexo tipicamente colonial (Ribeiro, 1997, p. 23-24).

Mas quem eram os profissionais de saúde que compuseram esta medicina tipicamente colonial? E mais: como era a organização e a fiscalização de seus ofícios? Como se pode perceber pelo que já foi dito até aqui, havia uma gama variada de praticantes de medicina no Brasil. Apesar de algumas características de tal grupo já terem sido referidas, há necessidade de defini-lo mais diretamente.

$\mathrm{Na}$ época colonial, existiram diversas categorias de pessoas que exerciam a medicina: os físicos, os cirurgiões, os barbeiros, os boticários, os aprendizes desses profissionais e os curandeiros em geral. Os físicos, como também eram chamados os médicos, bem como os cirurgiões-diplomados, formavam-se principalmente em Coimbra, e os poucos que vieram para os trópicos ocuparam cargos na administração colonial, sobretudo no Senado da Câmara ou nas tropas. Ao físico cabia a função de curar, enquanto que ao cirurgião, a de exercer a cirurgia. No entanto, devido à falta 
destes profissionais, que normalmente eram encontrados apenas nos principais centros populacionais, suas atribuições confundiam-se na prática cotidiana, uma vez que não era raro encontrar cirurgiões desempenhando atividades de cura (Machado et alli, 1978, p. 29). O mesmo acontecia com os boticários, encarregados do preparo e comercialização dos medicamentos prescritos pelos físicos e que, por um lado, comumente receitavam remédios e, por outro, deparavam-se constantemente com médicos, cirurgiões, barbeiros e droguistas (mercadores de drogas) realizando as funções de seu ofício (Marques, 1999, p. 176). Os barbeiros eram indivíduos que, além de cortar o cabelo e fazer a barba, praticavam pequenas cirurgias como a sangria, a extração de dentes e a aplicação de ventosas e sanguessugas (Salles, 1971, p. 52-53). Aos curandeiros, como os índios e negros mencionados, somavam-se indivíduos de todo tipo: padres jesuítas, senhores de engenho, mulheres do povo, letrados que aprenderam um pouco da arte de curar nos guias médicos populares que circulavam pela colônia, vigários e charlatães, que eram sempre os primeiros procurados pelo povo, que só recorria aos diplomados quando a terapêutica empírica e mística fracassava. A terapêutica desse vasto grupo consistia quase sempre no uso da flora medicinal brasileira e na invocação do sobrenatural (Santos Filho, 1947, p. 152-155).

Mas não se deve pensar que a falta de incentivo da metrópole nas questões de prevenção da saúde coletiva implicou num completo abandono da organização da medicina, mesmo porque foram criadas instituições para o controle da prática médica no Brasil. Com a falta de indivíduos diplomados, a metrópole concedia, mediante um exame junto aos delegados do Físico-Mor e do Cirurgião-Mor do Reino7, "licenças" ou

\footnotetext{
${ }^{7}$ Cargos que funcionaram no Brasil desde o início da implantação da administração ultramarina (o primeiro delegado do Físico-Mor no Brasil foi o licenciado Jorge Fernandes, que chegou à Bahia em 1553) até 17 de junho de 1782 , quando foi criada a Junta do Protomedicato. Esta, por sua vez, após ter transformado seu nome para Real Junta do Protomedicato em 1799, foi extinta logo após a chegada da Família Real portuguesa ao Brasil, quando se
} 
"cartas de habilitação" a indivíduos que já praticavam e desejavam legalizar o exercício da medicina, desde que comprovassem experiência de ao menos quatro anos (Nava, 2003, p. 48-49). Os delegados também fiscalizaram a prática de médicos, cirurgiões, barbeiros, enfim, de todos os que possuíam licença para exercer a medicina, além de combater o curandeirismo e de fiscalizar o comércio e a conservação de medicamentos, com visitas periódicas às boticas (Santos Filho, 1947, p. 299).

Este foi basicamente o quadro da arte da curar até o início do século XIX, quando um novo tipo de medicina começou a ganhar formas no Brasil: a medicina social. Restam ainda, no entanto, algumas questões em aberto, entre elas: se não havia um projeto de prevenção da saúde urbana, como teria ocorrido durante o oitocentos com a medicina social, quais as condições de salubridade apresentadas pelo Rio de Janeiro no período que antecedeu a chegada de Dom João? Ou ainda, como aqueles que estiveram no Rio de Janeiro no período do vice-reinado registraram as condições de saúde da urbe carioca e de seus habitantes?

\section{Condições de saúde no Rio de Janeiro dos vice-reis}

Durante o século XVIII, muitos dos que viveram ou simplesmente passaram pelo Rio de Janeiro consideraram o clima da cidade um dos principais fatores de produção e disseminação das doenças que acometiam a população, opinião partilhada principalmente pelos europeus, originários de um clima mais ameno, típico das regiões temperadas (Cavalcanti, 2004, p. 37). Mas o clima da cidade não foi sempre referenciado pelos europeus como insalubre e doentio: no Brasil quinhentista e seiscentista, os

restabeleceram os cargos de Físico-Mor e Cirurgião-Mor. No entanto, mesmo com a criação da Junta, suas atribuições permaneceram idênticas às da Fisicatura e Cirurgicatura Mores (Cf: Santos Filho, 1947, p. 297-300).

Brasiliana - Journal for Brazilian Studies. Vol. 2, n.2 (Nov 2013). ISSN 2245-4373. 
viajantes estrangeiros que estiveram nos trópicos descreveram, em suas relações de viagem, um clima bastante salubre, agradável e temperado, condições que contribuíam para tornar o Novo Mundo um "paraíso terrestre", como afirmou Américo Vespúcio em sua narrativa "Novus Mundus", publicada em 1503. Nicolas Barré, francês que acompanhou o cavaleiro da Ordem de Malta Nicolau Durand de Villegaignon ao Rio de Janeiro, cuja embarcação entrou na baía de Guanabara em novembro de 1555 para dar início ao projeto de edificação da França Antártica no Brasil, ratifica a sensação de um clima ameno e saudável:

[...] o ar é temperado, tendendo mais para o calor que para o frio. $\mathrm{O}$ verão começa no mês de dezembro, quando o sol está sob o trópico. Durante essa estação, todas as tardes chove e troveja durante três horas; no restante do dia faz, como dizem os nativos, o mais belo tempo do mundo. Eis o que tenho a dizer sobre [...] a salubridade e a disposição do ar (França, 1999b, p. 21).

Mas esta situação começa a mudar a partir da metade do século XVII: a tópica do clima temperado e salubre, mesmo que ainda presente nas narrativas de viagem seiscentistas e alvo de poucas contestações, passa a concorrer com descrições de um clima pouco agradável e bastante quente, percepção que se tornaria bem mais frequente durante o século seguinte; ${ }^{8}$ como afirma Jean Marcel Carvalho França:

\footnotetext{
${ }^{8}$ Ao longo do século XVII, juntamente com a mudança de percepção sobre o clima do Brasil, a metáfora do "paraíso" é, em larga medida, deixada de lado, passando a ocupar seu lugar a metáfora da "primavera eterna" (França, 2010, p. 16).
} 
[...] todavia, ao longo do século XVIII, malgrado a persistência da percepção do clima temperado e da reafirmação dessa ideia, o calor dos trópicos passa, num crescendo, a realmente tocar os visitantes estrangeiros e, sobretudo, a parecer-lhes bastante inóspito e insalubre. [...] O "quase paraíso" de Vespúcio, no entanto, por sorte não era composto somente pelo clima, que de ameno e salubre no século XVI passou, no final do século XVIII, a merecer a reputação de excessivamente quente e, o que é pior, insalubre (França, 1999b, p. 17).

Este é o clima que o tenente espanhol Juan Francisco de Aguirre, ao visitar o Rio de Janeiro em 1782, descreveu em sua narrativa de viagem:

[...] a palidez estampada no semblante dos habitantes deixa claro que essa região é péssima para a saúde. Há quem afirme que isso se deve à temperatura, outros dizem que à alimentação, há ainda os que culpam a falta de ventilação e a diminuição das ventanias. A temperatura realmente é bastante elevada. Durante o verão, o termômetro, instalado no alto do castelo de São Sebastião, nunca marca menos do que $82^{\circ} \mathrm{F}$, subindo até $86^{\circ}$. No inverno, os termômetros dificilmente marcam menos de $60^{\circ} \mathrm{F}$. Essa temperatura, somada à alimentação, à falta de ventilação, ao curso regular dos ventos e à atmosfera, produz as deploráveis condições de saúde da população dessa cidade (França, 1999b, p. 164-165). 
Dez anos após a passagem de Aguirre pelo Rio de Janeiro, o inglês Samuel Holmes também relata que "o clima é quente e insalubre" (França, 2000, p. 254). À insalubridade climática, retratada a partir do setecentos, soma-se a péssima localização da cidade no que tange ao ineficiente controle da disseminação de doenças. Por ter sido a urbe construída em um terreno circundado por montanhas, o que dificultaria a circulação dos ventos pela região citadina, é comum entre aqueles que se encontravam no Rio de Janeiro a ideia de que o ar seria maléfico à saúde dos habitantes; como afirma o tenentecapitão inglês Watkin Tench, que chegou ao Rio de Janeiro em 4 de setembro de 1787, “a cidade de São Sebastião situa-se do lado oeste do porto, num terreno baixo e insalubre, rodeado por montanhas. Tal localização impede a livre circulação do ar e expõe os habitantes a febres intermitentes e a doenças pútridas" (Id., 1999b, p. 189). Também queixa-se do ar o vice-rei Marquês de Lavradio, em carta enviada a João Gomes de Araújo, de 23 de junho de 1770, em que diz: "não tenho passado bem porque o ar que aqui se respira é sumamente prejudicial à saúde" (Lavradio, 1975, p. 188).

Uma das grandes causas da impureza do ar era a estagnação das águas em solo fluminense. Além dos alagadiços e mangues que circundavam a cidade, ambientes em que, como diz o Marquês de Lavradio, "com o extraordinário calor do sol se lhes corrompem as águas, onde nasce estarmos respirando um ar sumamente impuro" (Id., p. 87), também as chuvas torrenciais acabavam por alagar as ruas, empoçando água em diversos locais. É o que atesta George Staunton, ao passar pela cidade em 1792: o visitante comenta que um "fator extremamente nocivo para a saúde dos cariocas é a existência, no interior da cidade, de muitas águas estagnadas. Inúmeros são os pântanos que precisam ser drenados e cobertos" (França, 1999b, p. 200). Combine o acúmulo de águas pelas ruas e o calor escaldante que o sol dos trópicos oferece ao Rio de Janeiro para se ter uma ideia da situação das vias públicas encontrada pelos habitantes e 
visitantes da cidade. O memorialista Luiz Edmundo define-as com a seguinte expressão: “cada rua é uma artéria úmida e podre, secando ao sol" (Edmundo, 1951, p. 11).

Tal podridão das ruas vinha também do fato de os habitantes locais utilizaremnas como depósito de imundices; tudo era jogado nas vias públicas. Arremessava-se nas ruas todo e qualquer tipo de porcaria do interior das casas, principalmente nas ruas da Vala e do Cano, que funcionavam como espécie de via de escoamento das águas para fora da cidade. Mas, como se pode imaginar, as imundices funcionavam como barreiras, acumulando água e dejetos pelos caminhos públicos: esta era a origem de seu fétido odor. O mesmo Luiz Edmundo descreve o estado deplorável dos caminhos urbanos naqueles tempos:

[...] o desvelo do Senado da Câmara não pode estender-se a todas as ruas da cidade. Fica entre três ou quatro das mais centrais, das mais concorridas, das mais passeadas pelo vice-rei. Triste e abandonada rua! Por vezes, em lugares onde não é intenso o trânsito, vê-se um verdoengo tapete de gramíneas desafiando o paladar dos animais, que nela vivem ou passeiam inteiramente à solta: cabritos, carneiros, porcos, cavalos, galinhas e perus. Ao mesmo tempo rua e pasto. E monturo, também; lugar onde se juntam, quase sempre, no mesmo sonho de decomposição, detritos de toda a natureza, animais mortos, a espurcícia das cozinhas, de envolta com as águas pútridas e até dejeções humanas. Não há nisto o menor exagero. [...] a rua, qualquer que ela seja em toda a cidade colonial, cheira mal. [...] só um nariz de todo insensível ao esterquilínio da centúria será capaz de entrar, heroicamente, sem uma contração, sem um só arrepio (Edmundo, 1951, p. 25-26). 
Como transparece na descrição de Luiz Edmundo, a rua era uma espécie de lixão. Não é, pois, por acaso que o oficial da marinha britânica James Kingston Tuckey, em visita à cidade em 1803, afirme que "as febres, se não são inteiramente causadas, são consideravelmente multiplicadas pelos vapores tóxicos que emanam da sujeira acumulada nas ruas. Por aqui, as janelas são escapes noturnos para todas as coisas que a casa acumulou durante o dia" (França, 2000, p. 270).

Outro grande problema de saúde originário das ruas decorria dos escravos que por elas circulavam, problema este apontado pelo vice-rei Marquês de Lavradio, que também determinou sua solução. Em relatório apresentado ao seu sucessor, Luiz de Vasconcelos, Lavradio assinala:

[...] havia mais nesta cidade o terrível costume de que todos os negros que chegavam da costa da África a este porto, logo que desembarcavam, entravam para a cidade, vinham para as ruas públicas e principais dela, não só cheios de infinitas moléstias, mas nus; como aquela qualidade de gente, em quanto não tem mais ensino, são o mesmo que qualquer bruto selvagem, no meio das ruas onde estavam sentados em umas tábuas, que ali se estendiam, ali mesmo faziam tudo o que a natureza lhes lembrava, não só causando o maior fétido nas mesmas ruas e suas vizinhanças, mas até sendo o espetáculo mais horroroso que se podia apresentar aos olhos (Relatório do Marques de Lavradio..., 1843, p. 450$451)$.

Brasiliana - Journal for Brazilian Studies. Vol. 2, n.2 (Nov 2013). ISSN 2245-4373. 
Para remediar esta situação, o vice-rei ordenou que todos os escravos "logo que dessem sua entrada na Alfândega pela parte do mar, tornassem a sair e embarcassem para o sítio chamado Valongo, que é no subúrbio da cidade, separado de toda a comunicação" (Relatório do Marques de Lavradio..., 1843, p. 451). Com isso, Lavradio procurou, além de privar os moradores do mencionado "espetáculo horroroso", conter a disseminação de doenças trazidas pelos negros, afastando os focos geradores das moléstias para longe de onde se concentrava a população local, ou seja, Lavradio procurou controlar a proliferação de enfermidades ao impedir a aglomeração de escravos doentes nas principais vias públicas fluminenses.

Mas a insalubridade de São Sebastião não se restringia apenas a suas ruas, ela estendia-se também às casas. Insalubridade decorrente, além dos hábitos anti-higiênicos da população, 9 ou dos "preguiçosos e sujos costumes dos colonos" (França, 2000, p. 261), como os denominou James Kingston Tuckey, das próprias construções. O que sempre chamou a atenção dos estrangeiros que visitaram o Rio de Janeiro foi a utilização de gelosias nas janelas das casas. Tais gelosias eram uma espécie de treliça de madeira bem fechada, localizada nas fachadas, que bloqueavam a visibilidade dos transeuntes para os domínios internos da morada, o que dificultava a passagem de ar para o seu interior, tornando-a mais deletéria. As ditas gelosias, com isso, diminuíam o contato das residências com a rua e rareavam a iluminação de seus cômodos, detalhe que lhes conferiam um aspecto sinistro e de clausura (França, 1999a, p. 18). O resultado, ao somarem-se o clima úmido e quente da cidade à pouca luminosidade e troca de ar do interior das casas, eram residências completamente inadaptadas às condições climáticas locais, residências tomadas pelo bolor, limo e mofo (Edmundo, 1951, p. 47-48).

\footnotetext{
${ }^{9}$ Como afirma Jurandir Freire Costa, "na Colônia, a conduta anti-higiênica dos habitantes era um dos empecilhos fundamentais à saúde da cidade. A administração procurava atacar a dificuldade com o auxílio de almotacés de limpeza. Esta ação vigilante da justiça operava no mesmo universo de punição que caracterizava a represália aos marginais. Ela era descontínua, fragmentar e, acima de tudo, não sabia prevenir” (Costa, 2004, p. 29).
}

Brasiliana - Journal for Brazilian Studies. Vol. 2, n.2 (Nov 2013). ISSN 2245-4373. 


\section{Primórdios da higiene pública como política de governo}

A despeito de toda essa falta de saúde que reinou durante a época colonial, no período dos vice-reis começa a se desenvolver um novo tipo de preocupação com a salubridade do Rio de Janeiro. O final do século XVIII marcou um período de transição entre a medicina colonial e a medicina social. Foi neste momento que o planejamento urbano começou a despontar como preocupação da administração do Senado da Câmara, que passou a ver no médico um consultor sobre os assuntos de doença (Machado et alli, 1978, p. 142-149). Assim, a Câmara organizou, em 1798, uma reunião com os melhores médicos da cidade para desvendar as causas da insalubridade do Rio de Janeiro. Neste encontro, cujos dados complementam o cenário das poucas condições de saúde da cidade e dos habitantes apresentado até aqui, os físicos foram consultados para responder as seguintes questões propostas pelo Senado:

$1^{\circ}$ Quais são as moléstias endêmicas da cidade do Rio de Janeiro e quais as epidêmicas. $2^{\circ}$ Se é uma das principais causas das primeiras e do mau sucesso das segundas, o clima nimiamente úmido e quente. $3^{\circ}$ Se são causas da umidade: $1^{\circ}$ a suma baixeza do pavimento da cidade relativamente ao mar e baía, que cerca pelos três lados de és-sudeste, nordeste e nor-nordeste, de sorte que apenas se eleva do nível das águas das marés cheias de 5 a 11 palmos desde as praias até a maior distancia delas no campo de Santana, distante do mar 700 braças; $2^{\circ}$ a pouca expedição que tem as águas das chuvas copiosíssimas, principalmente de verão, e enxugadas então quase só à força do grande calor do sol, 
mas em muitas partes sempre estagnadas; $3^{\circ}$ a pouca circulação do ar pelas ruas da cidade e interior dos edifícios. $4^{\circ}$ Se são causas do calor: $1^{\circ}$ o impedimento que fazem à entrada dos quotidianos ventos matutinos ou terrais que sopram da parte do nordeste, norte e noroeste, os morros que correm de São Bento até São Diogo, na direção de és-nordeste, e à dos vespertinos ou virações mais fortes que os primeiros, constantes da parte do sudeste, sul e sudoeste, os morros do Castelo, Santo Antônio e Fernando Dias paralelos aos outros, de sorte que fica a cidade situada entre as duas cordas dos ditos morros, e inteiramente ao abrigo dos ventos; $2^{\circ}$ a direção das ruas ao nordeste e sudoeste de sorte que todas as casas são banhadas do sol inteiramente de manhã e de tarde. $5^{\circ}$ Se são causas das mesmas doenças: $1^{\circ}$ as imundices que se conservam dentro da cidade; $2^{\circ}$ as águas estagnadas nos seus arrabaldes, como em Mataporcos e Catete, pela baixeza do mesmo terreno. $6^{\circ}$ Quanto deverá ser elevado o pavimento da cidade e os edifícios para remediar aquela umidade e haver saída para as imundices. $7^{\circ}$ Quais são as outras causas morais e dietéticas das ditas doenças (O PATRIOTA, v. 1, n. 1, jan. 1813, p. 58-59).

De acordo com o médico Manoel Joaquim Marreiros, um dos consultados pela Câmara, por detrás da insalubridade do Rio de Janeiro existiria tanto uma "causa universal", de ordem natural, quanto causas "não-naturais", produzidas pelo homem. A dita causa natural era o clima da cidade: "quente", "úmido" e com "contínua variação da temperatura atmosférica". O clima seria ainda mais prejudicial ao combinar-se com a localização da urbe: "circulada por uma cadeia de serras [...], mananciais de 
copiosíssimas águas, as quais [...] em muitas partes estagnam, pela pouca inclinação do terreno, todo baixo a respeito do nível do mar, evaporando-se lentamente por falta do movimento do ar: este degenera da sua pureza" (O PATRIOTA, v. 1, n. 1, jan. 1813, p. 60). Aliado a isso tudo, atuavam também as causas "não-naturais":

1a. a direção de algumas ruas dispostas a estorvar que transitem livremente pelas casas de tarde a viração, e de manhã o terral, únicos corretivos do vicio do ar; $2^{\mathrm{a}}$. a mal entendida construção de casas com pequena frente e grande fundo, própria a diminuir os pontos de contato de ar externo com o interno; e sendo assim 3a. o terreno naturalmente úmido sobre que assentam as ditas casas, feito de pior condição pelas muitas águas sujas indiscretamente lançadas nas chamadas áreas das casas, as quais não obstante serem descobertas, mal chega algum raio do sol perpendicular e menos alguma partícula do ar livre; $4^{a}$. o desasseio das praças proveniente dos despejos, cujos eflúvios voltam para a cidade envoltos com os ventos, e os podem fazer pestíferos; as igrejas loucamente recheadas de cadáveres por uma indiscreta devoção; a Vala, o Cano, a cadeia, os esterquilínios vagos, enfim, tantos depósitos de imundices (O PATRIOTA, v. 1, n. 1, jan. 1813, p. 62-63).

O médico ainda aponta que a má alimentação dos fluminenses contribuiria para intensificar os seus problemas de saúde, alertando que "é muito nocivo o uso do peixe, facílimo a corromper-se" (O PATRIOTA, v. 1, n. 1, jan. 1813, p. 63). Contudo, após delimitar os possíveis problemas de salubridade do Rio de Janeiro, Marreiros propõe algumas soluções: 
[...] não podendo evitar-se o dano que provém de ficar a cidade abafada pelas montanhas, destas, contudo, se pode tirar algum partido fazendo que sejam cobertas de arvoredo, o qual mostra a experiência quanto aí prospera. [...] $1^{\circ}$ exteriormente, em elevar e abaixar o terreno nos diversos lugares, como for conveniente para evitar o estagno das águas; interiormente, em examinar se as casas se acham com os seus canos desembaraçados para a expedição das águas da chuva, admoestando os habitantes (vista a impossibilidade de coação a este respeito) para que não lancem outras impuras nas suas pequenas áreas, pelo dano que lhes resulta de semelhante desatino. $2{ }^{\circ}$ Em providenciar ao despejo da cidade, de sorte que se evite a fazer-se ao longo das praias, donde não havendo saída pela fraca ação da maré em tais sítios se exala o mais pestífero cheiro que todos experimentam. [...] Já tem sido lembrado o arbítrio das barcas, que recebendo os despejos por pontes as mais extensas, que possível for, na hora da vazante, sejam conduzidas a reboque até fora da Barra, onde por válvulas se desonerem. [...] fazer o despejo quotidiano da cadeia, cujo cano devia ser entulhado; da mesma sorte a respeito dos Hospitais. Não deve esquecer a reforma e concerto da Vala e Cano, de sorte que deixem de ser um depósito infernal de imundice (O PATRIOTA, v. 1, n. 1, jan. 1813, p. 65-67).

Tal qual Manoel Joaquim Marreiros, outros dois médicos apresentaram seus pareceres sobre as questões levantadas pela Câmara: Bernardino Antonio Gomes e Antonio Joaquim de Medeiros, cujos problemas levantados e as soluções apontadas assemelham- 
se bastante àqueles propostos por Marreiros. Basicamente, Gomes e Medeiros retomam em seus pareceres os transtornos de ordem natural, apontando entre eles o clima, o calor, a umidade, a localização da urbe entre os morros, etc. Os dois médicos também referem-se àqueles criados pelos moradores, tais como a imundice das ruas, as águas estagnadas pela precariedade das vias de escoamento, a construção de casas de baixa elevação em relação ao solo, o que acarretaria em constante umidade às residências, a estreiteza das ruas, o que dificultaria a circulação de ar, a péssima alimentação da população, somando-se ao peixe o consumo de bananas, mandioca, arroz, feijão, malte e de carne seca. Mas, além disso, ambos os físicos refletem sobre outros problemas também criados pelos próprios moradores, problemas tidos como empecilhos à saúde dos habitantes locais. Em primeiro lugar, ressaltam a imundíce doméstica originada da escravatura, pois, uma vez que muitos escravos dividiam pequenos ambientes onde habitavam, "qual será o ar destes pequenos aposentos respirado por muitas pessoas por natureza e condição imundas?" (O PATRIOTA, v. 1, n. 2, fev. 1813, p. 60). Segundo, destacam a vida sedentária dos habitantes, pois "o exercício é depois do alimento o principal esteio da saúde, e daqui vem que, tudo o mais igual, os que fazem mais exercício são os que gozam melhor saúde" (Id., p. 62). Por fim, apontam a prostituição, proveniente do luxo e da depravação dos costumes, "de maneira que dentro da cidade não faltam casas públicas onde a mocidade vai estragar sua saúde e corromper os costumes de uma boa educação, contraindo novas enfermidades e dando causas para outras tantas" (O PATRIOTA, v. 1, n. 3, mar. 1813, p. 10-11).

Apesar, porém, da grande semelhança entre os pareceres dos três médicos, há ao menos uma diferença entre suas opiniões no tocante à pelo menos uma questão: o que fazer com os morros que circundam o Rio de Janeiro? Para Marreiros, como já apontado, era necessário melhor arborizá-los, pois isso traria maior regeneração do ar, o que 
resultaria na melhora de sua qualidade. Já para os outros dois físicos era necessário "que se arrasasse o morro do Castelo e o de Santo Antônio" (Id., p. 13), ou ao menos "que se demolisse parte de um e de outro morro", o que facilitaria a circulação do ar pela cidade (O PATRIOTA, v. 1, n. 2, fev. 1813, p. 61).

Como se vê, durante o vice-reinado começa a delimitar-se um novo tipo de preocupação médica com a cidade, preocupação que, apesar de passar pela ideia de planejamento sanitário, ainda não é o suficiente para definir um novo tipo de medicina, que se consolidaria no Brasil apenas durante o século XIX: a medicina social. Isso porque, neste período em que política governamental da higiene pública parece surgir no Brasil, a medicina ainda tem a função de legitimar o saber do poder institucional, na "passividade de um saber-resposta" que buscava solucionar, consultivamente, os problemas e questões apresentados pelo poder central. Assim, a medicina ainda não era compreendida, como acontecerá com a medicina social no oitocentos, "como uma prática política específica, como um poder especializado que deve assumir a responsabilidade dos indivíduos e da população atuando sobre as condições naturais e sociais da cidade" (Machado et alli, 1978, p. 149).

\section{Considerações finais}

Apesar da preocupação dos governantes locais em tomar medidas que investissem na salubridade do Rio de Janeiro, preocupação encontrada principalmente durante a segunda metade do século XVIII, as providências tomadas pelos vice-reis são ainda bastante acanhadas, ainda mais se comparadas àquelas que serão colocadas em prática depois da chegada da corte, em 1808; como salienta Luiz Edmundo, após o governo do vice-rei Luiz de Vasconcelos: 
[...] faz-se, no entanto, pouco, muito pouco. Aterra-se a Lagoa do Boqueirão, traça-se o Passeio Público. Até o Sr. Conde de Rezende e D. Fernando Portugal, que lhe sucedem, nada ou quase nada mais se faz. Melhorar o país? Para que? O Sr. Conde dos Arcos tem um governo rápido. Fugindo aos soldados de Napoleão, chega, depois disso, a Corte portuguesa, de Lisboa. Ano de 1808. A cidade não mudou. É a mesma. [...] A cidade, na alvorada do século XIX, é o que era há 200 anos atrás: uma estrumeira (Edmundo, 1951, p. 10-12).

Desse modo, o que pôde ser visto no decorrer deste artigo foi um Rio de Janeiro colonial de contornos bastante inóspitos: um território deletério, com suas ruas e casas tanto sujas quanto mal construídas. Uma urbe insalubre em que a medicina profissionalizada pouco intervinha, resumindo-se a combater as moléstias disseminadas em vez de preveni-las. No entanto, se a precariedade do Rio de Janeiro começa a ser problematizada pelas autoridades em fins do Setecentos, foi somente com a transferência dos Bragança para os trópicos, no início do século XIX, que a capital brasileira passou a receber um cuidado mais especial e intenso. A partir de então, a medicina passou por um processo de um novo desenvolvimento institucional, ganhando novas atribuições que convergiram em direção a uma prática de intervenção social centrada em novas estratégias de controle e normatização da sociedade, a saber: a civilizatória. Nesse sentido, a medicina social do século XIX, diferentemente do tipo de medicina praticado durante o período colonial, passou a atuar na prevenção da saúde da cidade e de seus habitantes, transformando-se de uma intervenção a posteriori sobre o 
indivíduo doente para uma prática de prevenção e manutenção de um estado contínuo de saúde, prática esta direcionada, por meio da higiene pública, para o âmbito social.

\section{Referências}

Barreto Filho, Mello; Lima, Hermeto. História da polícia do Rio de Janeiro: aspectos da cidade e da vida carioca (1565-1831). Rio de Janeiro: Editora S. A. A NOITE, 1939.

Bicalho, Maria Fernanda. A cidade e o império: o Rio de Janeiro no século XVIII. Rio de Janeiro: Civilização Brasileira, 2003.

Cavalcanti, Nireu. O Rio de Janeiro Setecentista: a vida e a construção da cidade da invasão francesa até a chegada da Corte. Rio de janeiro: Jorge Zahar Ed., 2004.

Costa, Emília Viotti da. Da monarquia à república: momentos decisivos. São Paulo: Editora UNESP, 2007.

Costa, Jurandir Freire. Ordem médica e norma familiar. Rio de Janeiro: Edições Graal, 2004.

Edmundo, Luiz. O Rio de Janeiro no tempo dos vice-reis. Rio de Janeiro: Editora Aurora, v. $1,1951$.

Foucault, Michel. "O nascimento da medicina social". In: . Microfísica do poder. Rio de Janeiro: Edições Graal, 1979.

França, Jean Marcel Carvalho. Literatura e sociedade no Rio de Janeiro oitocentista. Lisboa: Imprensa Nacional/Casa da Moeda, 1999.

. "O mundo natural e o erotismo das gentes no Brasil Colônia: a perspectiva do estrangeiro". In: Revista Topoi, v. 11, n. 20, jan.-jun. 2010.

. Outras visões do Rio de Janeiro colonial: antologia de textos, 1582-1808. Rio de Janeiro: José Olympio, 2000.

. Visões do Rio de Janeiro colonial: antologia de textos, 1531-1800. Rio de Janeiro: Ed. UERJ/José Olympio, 1999. 
Freyre, Gilberto. Sobrados e mucambos: decadência do patriarcado rural e desenvolvimento do urbano. São Paulo: Global, 2004.

Holanda, Sergio Buarque de. Raízes do Brasil. São Paulo: Companhia das Letras, 1995.

Lavradio, Marquês do. Cartas do Rio de Janeiro (1769-1776). Rio de Janeiro: Arquivo Nacional, 1975.

Machado, Roberto et alli. Danação da norma: medicina social e constituição da psiquiatria no Brasil. Rio de Janeiro: Edições Graal, 1978.

Marques, Vera Regina Beltrão. Natureza em boiões: medicinas e boticários no Brasil setecentista. Campinas, SP: Editora da Unicamp/Centro de Memória-Unicamp, 1999.

Nava, Pedro. Capítulos da história da medicina no Brasil. São Paulo: Oficina do Livro Rubens Borba de Moraes, 2003.

O Patriota, jornal literário, político, mercantil do Rio de Janeiro, v. 1, n 1-3, jan.-mar. 1813.

"Relatório do Marques de Lavradio, vice-rei do Rio de Janeiro, entregando o governo a Luiz de Vasconcellos e Sousa, que o sucedeu no vice-reinado". In: Revista Trimestral de História e Geografia ou Jornal do Instituto Histórico e Geográfico Brasileiro, v. 16, jan. 1843.

Ribeiro, Lourival. Medicina no Brasil colonial. Rio de Janeiro: GB, 1971.

Ribeiro, Márcia Moisés. A ciência dos trópicos: a arte médica no Brasil do século XVIII. São Paulo: Editora Hucitec, 1997.

Salles, Pedro. História da medicina no Brasil. Belo Horizonte: Editora G. Holman LTDA, 1971.

Santos Filho, Lycurgo. História da medicina no Brasil: do século XVI ao século XIX. São Paulo: Editora Brasiliense LTDA, v. 1, 1947.

. "Medicina colonial". In: HOLANDA, Sergio Buarque de (dir.). História geral da civilização brasileira: a época colonial. São Paulo: Difusão Européia do Livro, tomo I, v. 2, 1960. 